\title{
PERENCANAAN PROTOTIPE MENARA PENDINGIN MINI UNTUK ALAT PENUKAR KALOR TIPE PLAT DATAR
}

\author{
YAFID EFFENDI \& ANGGI ARDYANTA SAPUTRA \\ Program Studi Teknik Mesin, Fakultas Teknik, Universitas Muhammadiyah Tangerang \\ Jl. Perintis Kemerdekaan I/33 Cikokol-Tangerang \\ E-mail: yafideffendi@yahoo.com
}

\begin{abstract}
Abstrak
Prototipe Menara Pendingin Mini salah satu alat penukar panas, dimana aliran fluida panas (air) akan dikontak langsung dengan fluida dingin (udara). Dengan menggunakan plat datar tipis sebagai media perpindahan panas yang bertujuan untuk memperluas permukaan perpindahan panas dimana fluida panas mengalir diatas plat dibantu dengan kipas untuk memperlambat laju aliran yang jatuh sehingga dengan memperlambat laju aliran maka energi panas yang hilang lebih besar. Tujuan penelitian ini untuk mengetahui berapa besar laju aliran dan koefisien laju aliran perpindahan panas plat datar. Penelitian ini dilakukan dengan menggunakan metode eksperimen dengan melakukan pengujian langsung pada prototype Mini Cooling Tower dengan menganalisa laju aliran dan koefisien laju aliran perpindahan panas. Laju Aliran 0.5 liter/menit yang diukur dalam interval waktu 5 menit. Dari hasil penelitian ini didapat bahwa laju aliran perpindahan panas plat datar q adalah $5,537 \mathrm{~W} / \mathrm{m}^{20} \mathrm{C}$ dan koefisien laju aliran perpindahan panas plat datar $h$ adalah $8.859 \mathrm{~W} / \mathrm{m}^{20} \mathrm{C}$. Laju perpindahan panas ini masih bisa ditingkatkan dengan memperluas dimensi permukaan plat ataupun dengan menggunakan kipas/fan blower sehingga temperatur yang keluar lebih rendah.
\end{abstract}

Kata kunci: Prototipe Menara Pendingin Mini, perpindahan panas, plat datar, air

\section{Pendahuluan}

Pada umumnya proses pendinginan dapat dilakukan dengan dua cara yaitu, dengan menggunakan fluida udara dan fluida air. Pemanfaatan fluida udara langsung sebagai media pendingin sering digunakan untuk pendinginan yang berkapasitas kecil contohnya seperti pada sepeda motor. Sedangkan untuk pendinginan yang berkapasitas sedang biasanya menggunakan pendinginan secara bertingkat dimana mesin didinginkan oleh oli kemudian oli tersebut didinginkan dengan air. Air itu sendiri disirkulasikan ulang yang terlebih dahulu didinginkan di Prototipe Menara Pendingin Mini (Prototype Mini Cooling Tower).

Dalam perencanaan ini, Prototipe Menara Pendingin Mini yang direncanakan merupakan tipe plat datar dimana plat tersusun secara horizontal dan fluida air mengalir diatas plat tersebut, pola aliran seperti ini untuk memperlambat laju aliran massa fluida panas (air) sehingga luas kontak permukaan perpindahan panas antara fluida panas dengan udara dapat diperbesar dan waktu persentuhan fluida panas dengan udara dapat diperbesar dan waktu persentuhan fluida panas dengan udara dapat diperpanjang. Dengan memperbesar permukaan sentuh dan memperpanjang waktu persentuhan antara fluida panas dengan udara dapat memperbesar laju perpindahan panas sehingga pembuangan energi panas dari Prototipe Menara Pendingin Mini ke udara dapat ditingkatkan.

Kemudian untuk mengetahui laju aliran dan koefisien laju aliran perpindahan panas pada perencanaan Prototipe Menara Pendingin Mini ini dapat dilakukan dengan menggunakan metode ekperimen dengan melakukan pengujian langsung pada prototype Mini Cooling Tower dengan menganalisa laju aliran massa udara, laju aliran massa air yang digunakan untuk menganalisa perpindahan panas yang terjadi pada suatu alat penukar panas. 


\section{Metode Penelitian}

Penelitian ini menggunakan metode eksperimen dengan melakukan pengujian langsung pada prototype Mini Cooling Tower. Alat ini merupakan alat yang dirancang dan disimulasikan untuk mengetahui laju aliran dan koefisien perpindahan panas pada plat datar.

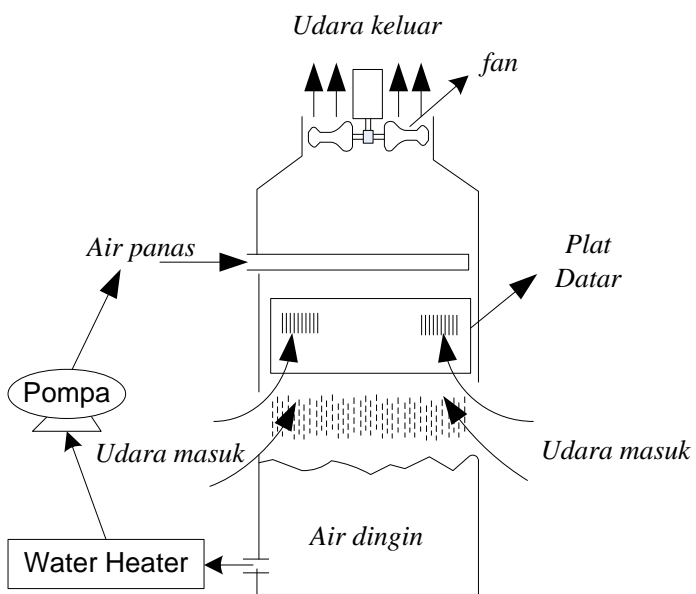

Gambar 1. Diagram Skematik Mini Cooling Tower

Penelitian ini menggunakan metode eksperimen dengan melakukan pengujian langsung pada prototype Mini Cooling Tower. Alat ini merupakan alat yang dirancang dan disimulasikan untuk mengetahui laju aliran dan koefisien perpindahan panas pada plat datar.

Berikut ini metode penelitiannya;

1. Menghidupkan mesin/sistem Mini Cooling Tower secara keseluruhan.

2. Masukan air kedalam bak penampung bawah.

3. Mejalankan pompa air, kemudian mengatur aliran air pada kran.

4. Menunggu air yang dipanaskan temperaturnya direservoir selama 10 menit

5. Membuka dan mengatur kran air pada saluran air yang temperaturnya telah dipanaskan direservoir.

6. Melakukan pendataan terhadap perubahan temperatur suhu pada menit ke $5,10, \ldots 25$.

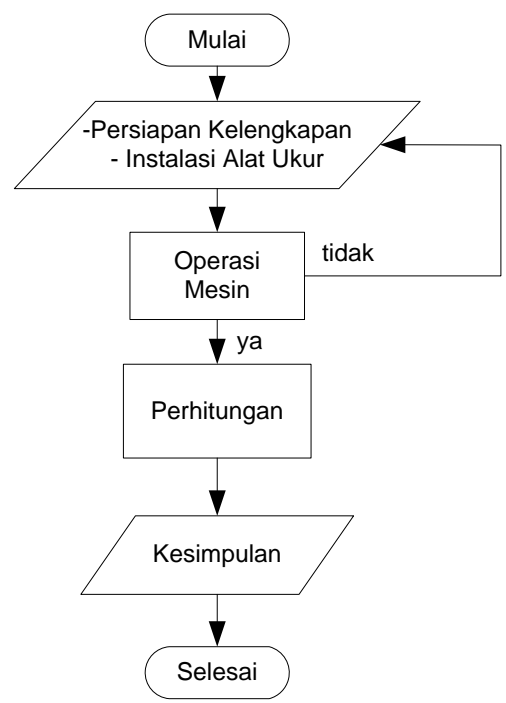

Gambar 2. Prosedur Pengambilan Data

\section{Bahan Yang Digunakan}

Komponen-komponen dari Menara Pendingin

1. Kerangka cooling tower

Kerangka pendukung cooling tower berfungsi untuk mendukung cooling tower agar dapat berdiri kokoh dan tegak. Kerangka pendukung cooling tower dapat dilihat pada Gambar 3 berikut ini.

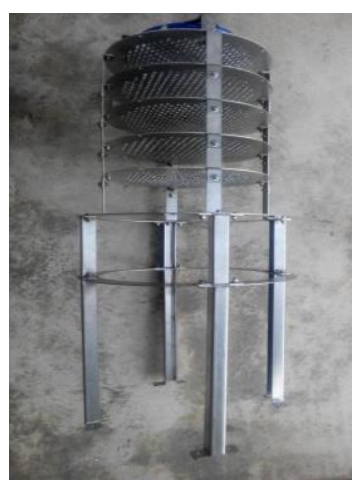

Gambar 3. Kerangka pendukung cooling tower

2. Bak penampung bawah

Bak penampung bagian bawah berfungsi untuk menampung air yang sudah diturunkan temperaturnya dan air tersebut dipompakan kembali ke atas bak ke penampungan atas. 
Bak penampungan bawah dapat dilihat pada Gambar 4 berikut ini.

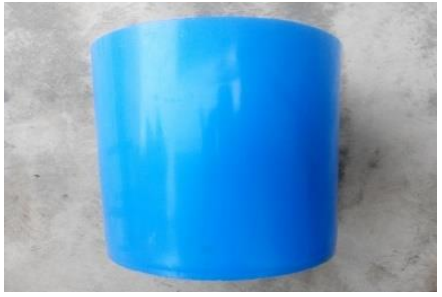

Gambar 4 Bak penampungan bawah

3. Plat datar

Pada bagian ini air dialirkan diatas plat secara external flow sehingga terjadi perpi ndahan panas konveksi akibat kontak langsung dengan aliran udara. Pada perencanaan menara pendingin ini terdapat 5 plat datar yang tersusun secara horizontal, yang bertujuan untuk memperluas permukaan perpindahan panas antara fluida panas dengan udara sehingga waktu persentuhan fluida panas dengan udara dapat diperpanjang. Plat datar dapat dilihat pada Gambar 5 berikut ini.

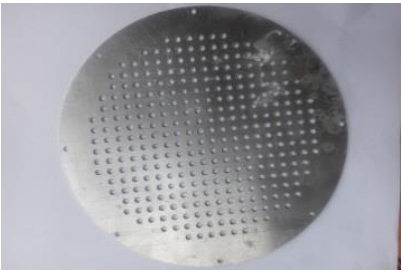

Gambar 5. Plat datar

4. Tong/ember plastik

Tong/ember plastik berfungsi sebagai rumah/cassing cooling tower. Tong/ember plastik dapat dilihat pada Gambar 6 berikut ini.

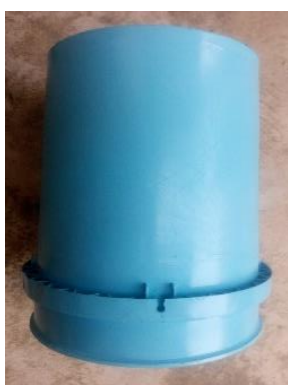

Gambar 6. Tong/ember plastik

5. Kipas/fan

Yafid Effendi \& Anggi Ardyanta Saputra
Kipas/fan yaitu merupakan bagian yang terpenting dari sebuah manara pendingin karena berfungsi untuk manarik/mendorong udara dingin dan mensirkulasikan udara tersebut di dalam menara untuk mendinginkan air. Kipas/fan dapat dilihat pada Gambar 7 berikut ini.

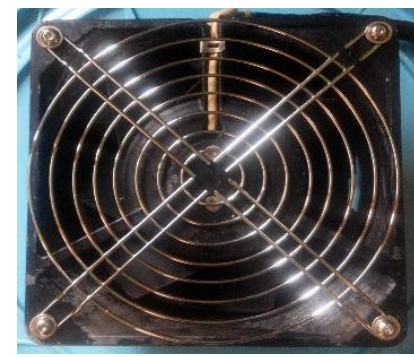

Gambar 7 Kipas/fan

6. Pompa air akuarium

Pompa akuarium yaitu berfungsi untuk memompa air dari bak penampungan bawah menuju mesin tabung pemanas kemudian jatuh di permukaan filler/plat datar alumunium kemudian disirkulasikan kembali. Pompa akuarium dapat dilihat pada Gambar 8 berikut ini.

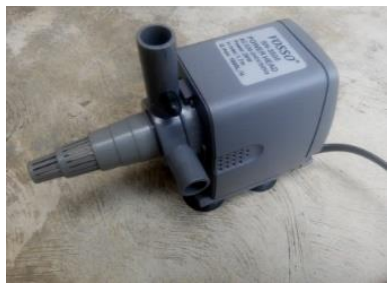

Gambar 8 Pompa air akuarium

7. Selang air

Selang air yaitu berfungsi untuk mengalirkan jalannya air yang diberi tekanan dari pompa pada mesin cooling tower ini. Selang air dapat dilihat pada Gambar 9 berikut ini.

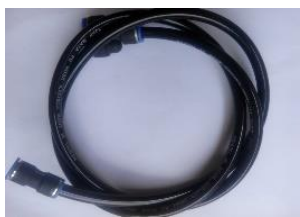

Gambar 9 Selang air

8. Shock/Elbow/Knee/L 
Shock/Elbow/Knee/L alat ini berfungsi untuk menyambung selang air dengan selang air yang lain atau dengan aksesori di tempat yang membutuhkan sambungan lurus atau sambungan belokan. Gambar Shock/Elbow/Knee//L dapat dilihat pada Gambar 10 berikut.

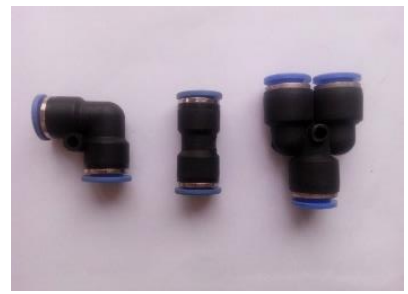

Gambar 10 Shock/Elbow/Knee/L

9. Sprinker/Nozel

Fungsi dari sprinker/nozel ini adalah untuk menyemprotkan air menjadi butiranbutiran kecil dengan tujuan untuk memperlebar luas bidang kontak antara air dan udara serta agar air dapat terdistribusi secara merata keseluruhan ruang didalam menara. Sprinker/Nozel dapat dilihat pada Gambar 11 berikut ini.

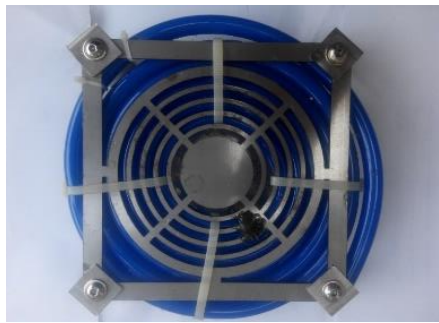

Gambar 11 Sprinker/Nozel

10. Nepel Kran air

Kran air yaitu alat yang dipakai untuk mengeluarkan air dari selang atau sistem instalasi air. Meskipun hanya kecil saja tapi ini berfungsi untuk mengatur jalan keluarnya air. Nepel kran air dapat dilihat pada Gambar 12 berikut ini.

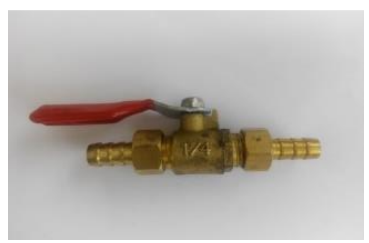

Gambar 12 Nepel kran air
11. Kabel dasi/cable tie

Kabel dasi/cable tie yaitu berfungsi untuk mengencangkan ikatan sekitar bundel kabel dan kawat. Gambar kabel dasi/cable tie ini dapat dilihat pada Gambar 13 berikut ini.

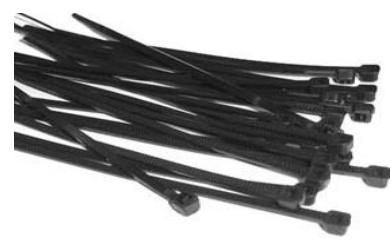

Gambar 13. Kabel dasi/cable tie

12. Bak penampung atas

Bak penampungan atas merupakan tempat penampungan air yang dipanaskan dengan heater sehingga mencapai temperatur $\mathrm{T}_{2}$ sebelum dialirkan ke plat datar. Pada bak penampungan atas juga terdapat bagian-bagian yang terdiri dari saluran pipa air masuk dan pintu air yang merupakan tempat keluarnya air dari bak yang selanjutnya dialirkan diatas plat. Pintu air ditempatkan pada bagian bawah bak, hal ini bertujuan untuk mempercepat air mengalir. Gambar bak penampungan atas dapat dilihat pada Gambar 14 berikut ini.

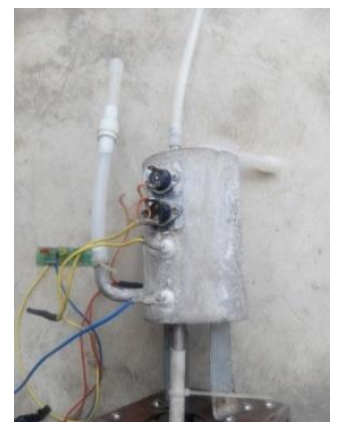

Gambar 14. Bak penampung atas

13. Kerangka bak benampung atas

Kerangka bak penampung atas ini berfungsi untuk mendukung tabung pemanas agar dapat berdiri kokoh dan tegak, kerangka bak penampungn atas ini seperti menara yang tinginya lebih dari lebarnya. Kerangka tabung pemanas dapat dilihat pada Gambar 15 berikut ini. 


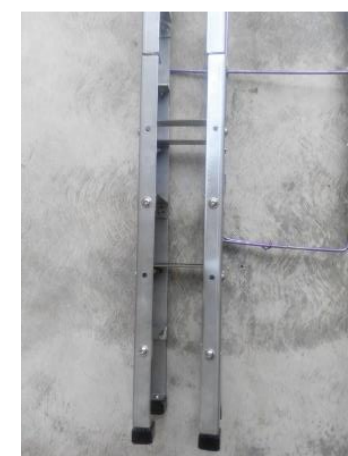

Gambar. 15 Kerangka bak penampung atas

\section{Alat Yang Digunakan}

\section{Thermometer digital}

Thermometer digital adalah sebuah alat untuk menyatakan suhu derajat panas dingin suatu benda yang digunakan untuk mengukur suhu. Dalam pengujian ini, thermometer digunakan untuk mengukur suhu air masuk dan air keluar pada menara pendingin (cooling tower) tersebut. Thermometer dapat dilihat pada Gambar 16 berikut ini.

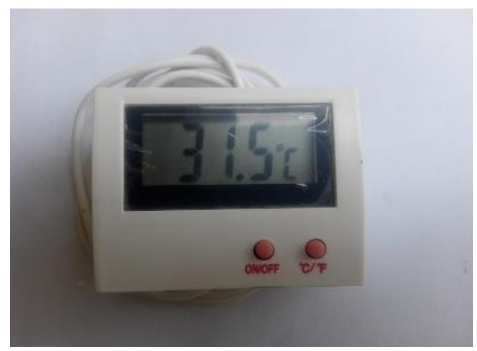

Gambar 16. Thermometer Digital

2. Stopwatch

Stopwatch merupakan sebuah arloji genggam yang dirancang untuk mengukur jumlah waktu yang telah berlalu dari waktu tertentu ketika di aktifkan sampai stopwatch tersebut di non aktifkan. Dalam pengujian ini stopwatch digunakan untuk menghitung waktu pada saat pengujian. Stopwatch dapat dilihat pada Gambar 17 berikut ini.

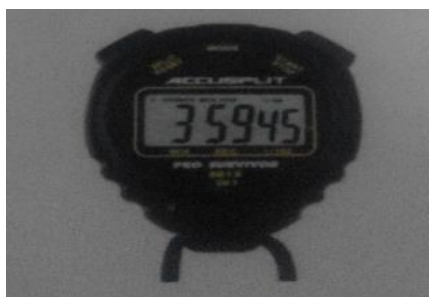

Gambar 17. Stopwatch

3. Jangka Sorong

Jangka sorong adalah alat yang digunakan untuk melakukan pengukuran terhadap suatu objek secara rinci. Jangka sorong dipakai untuk pengukuran panjang, lebar, tinggi, dan kedalaman. Dalam penelitian ini jangka sorong digunakan untuk mengukur bagian-bagian yang dibutuhkan untuk membuat konstruksi menara pendingin (cooling tower) yang akan dibuat. Jangka sorong dapat dilihat pada Gambar 18 berikut ini.

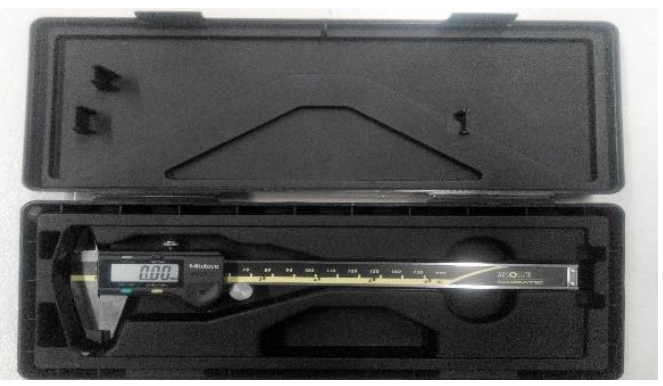

Gambar 18 . Jangka sorong

4. Meteran

Meteran juga dikenal sebagai pita ukur atau tape atau bisa disebut juga roll meter ialah alat ukur panjang yang bisa digulung. Gambar meteran dapat dilihat pada Gambar 3.19 berikut ini.

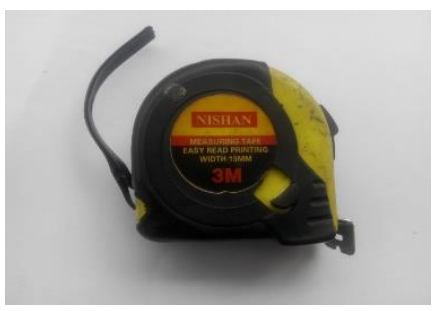

Gambar 19. Meteran 


\section{Anemometer digital}

Anemometer adalah sebuah perangkat yang digunakan untuk mengukur kecepatan angin, dan merupakan salah satu yang banyak dipakai dalam bidang metorologi dan geofisika atau stasiun perkiraan cuaca. Dalam pengujian ini, anemometer digunakan untuk mengukur kecepatan angin yang dihasilkan oleh kipas/fan pada cooling tower tersebut. Anemometer dapat dilihat pada Gambar 20 berikut ini

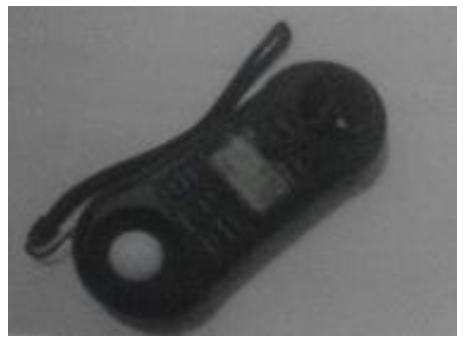

Gambar 20. Anemometer digital

6. Tabung/gelas ukur air

Tabung/gelas ukur air adalah alat yang dipakai untuk mengukur volume segala benda (air). Tabung/gelas ukur air dapat dilihat pada Gambar 21 berikut ini.

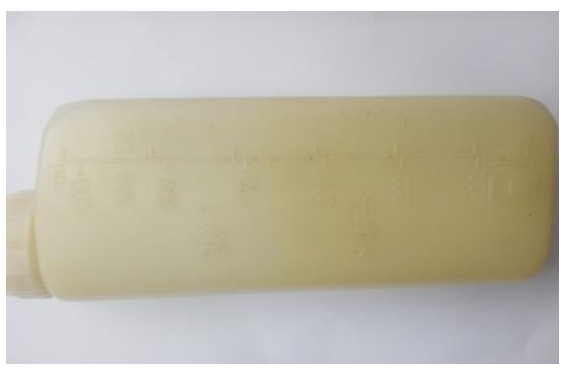

Gambar 21 Tabung/gelas alat ukur air

\section{Kunci L}

Kunci L yaitu alat yang berfungsi untuk mengencangkan atau membuka baut dari komponen mesin cooling tower yang kepalanya menjorok ke dalam, karena itulah penampang kunci ini berbentuk segienam atau hexagonal dan bintang. Kunci L dapat dilihat pada Gambar 22 berikut ini.

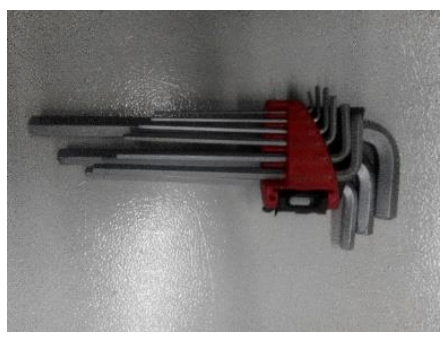

Gambar 22. Kunci L

8. Kunci pas

Kunci pas dan kunci ring digunakan untuk mengencangkan atau membuka baut atau mur yang berbentuk segi enam (hexagonal) dari komponen mesin cooling tower. Kunci pas dapat dilihat pada Gambar 23 berikut ini.

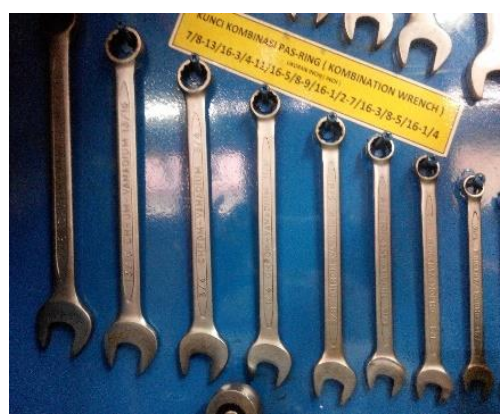

Gambar 23. Kunci pas

\section{Tang Kombinasi}

Tang kombinasi yaitu alat yang berfungsi untuk menjepit kawat atau kabel pada proses perakitan mesin cooling tower. Tang Kombinasi dapat dilihat pada Gambar 24 berikut ini.

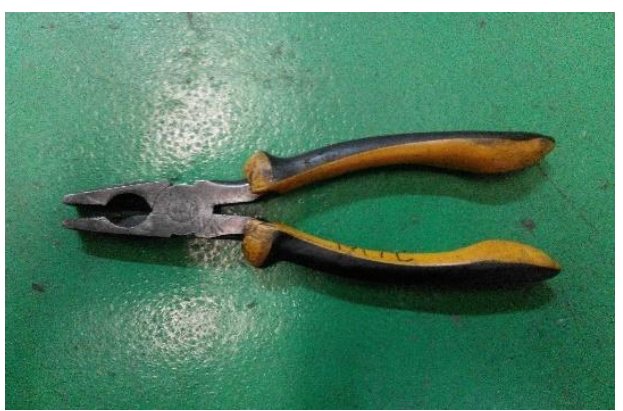

Gambar 24. Tang Kombinasi 


\section{Tang Pemotong}

Tang pemotong yaitu alat yang berfungsi untuk memotong kawat dan kabel pada proses perakitan mesin cooling tower. Tang pemotong dapat dilihat pada Gambar 25 berikut ini.

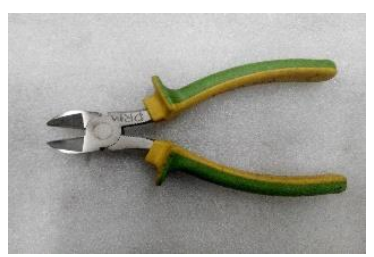

Gambar 25 Tang pemotong

\section{Tang Rivet}

Tang rivet yaitu terdapat dua tipe yaitu tipe biasa dan fleksibel, kedua fungsinya sama yaitu untuk memasang paku keling. Tang rivet dapat dilihat pada Gambar 26 berikut ini.

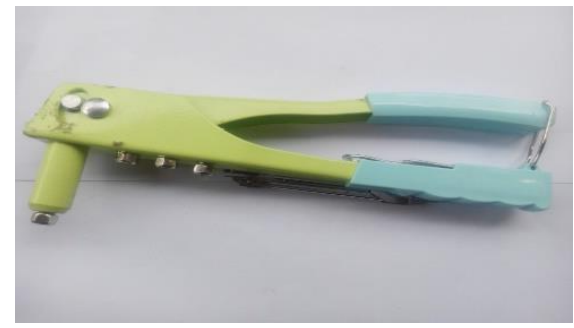

Gambar 26 Tang rivet

12. Mesin bor tangan

Mesin bor tangan suatu jenis mesin geraknya memutar alat pemotong yang arah pemakanan mata bor hanya pada sumbu mesin tersebut (pengerjaan pelubangan). Fungsi mesin bor tangan ini membuat pengerjaan lubang di perencanaan mesin menara pendingin. Mesin bor tangan dapat dilihat pada Gambar 27 berikut ini.

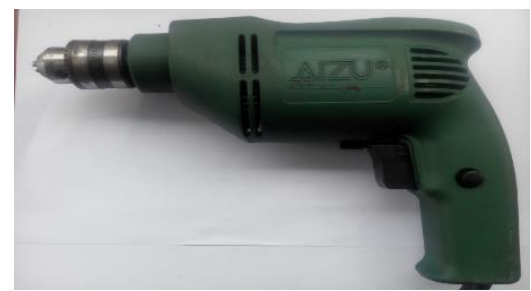

Gambar 27. Mesin bor tangan

\section{Jangka}

Jangka adalah alat yang digunakan untuk menggambar lingkaran atau busur. Alat ini juga dapat digunakandalam matematika, gambar teknis, navigasi dan lain-lain. Jangka dapat dilihat pada Gambar 28 berikut ini.

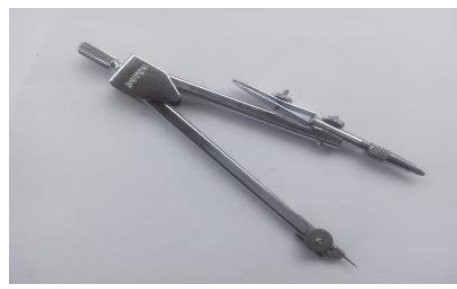

Gambar 28. Jangka

\section{Hasil dan Pembahasan}

Dari pengujian yang telah dilakukan terhadap mesin menara pendingin (cooling tower) tersebut maka diketahui:

Tabel. 1 Data Penelitian

1. Media Pendingin : Air sumur

2. Dimensi $\mathrm{P} \times \mathrm{L} \times \mathrm{T} \quad: 0,8 \mathrm{~m} \times 0,3 \mathrm{~m} \times 0,3 \mathrm{~m}$

3. Diameter tabung : $0,3 \mathrm{~m}$

4. Waktu pengujian :5 menit

5. Temperatur air normal $: 29^{\circ} \mathrm{C}$

6. Diameter selang in : $6,5 \times 10 \mathrm{~mm}$

7. Diameter selang out : $6,5 \times 10 \mathrm{~mm}$

8. Debit air $\quad: 8,333 \mathrm{~m}^{3} / \mathrm{s}$

9. Kapasitas bak penampung atas: 0,5 liter

10.Kapasitas bak penampung bawah: 10 liter

11.Motor kipas/fan : 48 watt

12.Pompa air $\quad: 1$ fase

\begin{tabular}{|l|l|l|l|l|l|l|l|}
\hline \multirow{2}{*}{$\begin{array}{c}\text { Aliran } \\
\text { Air }\end{array}$} & \multicolumn{2}{|c|}{$\begin{array}{c}\text { Kecepatan } \\
\text { Udara } \\
(\mathrm{m} / \mathrm{s})\end{array}$} & \multicolumn{2}{|c|}{ Udara $\left({ }^{\circ} \mathrm{C}\right)$} & \multicolumn{2}{|c|}{ Air $\left({ }^{\circ} \mathrm{C}\right)$} & \multirow{2}{*}{ Waktu } \\
\cline { 2 - 7 } & Out & In & \multicolumn{2}{|c|}{} \\
\hline L/m & $v 1$ & $v 2$ & Th,i & Th,o & Tc,i & Tc,o & \\
\hline 0,5 & 1,7 & 0,6 & 28 & 25 & 32 & 30,7 & 5 menit \\
\hline 0,5 & 1,7 & 0,6 & 28 & 25,5 & 31,8 & 29,7 & 5 menit \\
\hline 0,5 & 1,7 & 0,6 & 28 & 26 & 31,5 & 29,5 & 5 menit \\
\hline 0,5 & 1,7 & 0,6 & 28 & 25,5 & 31,5 & 29,5 & 5 menit \\
\hline 0,5 & 1,7 & 0,6 & 28 & 25 & 31,5 & 29 & 5 menit \\
\hline
\end{tabular}




\section{Perhitungan Data Hasil Hasil Pengujian}

Untuk contoh perhitungan diambil dari data hasil pengujian pada laju aliran volume sebesar 0,5 liter/menit dengan mengambil nilai rata-rata untuk masing-masing temperatur pengujian

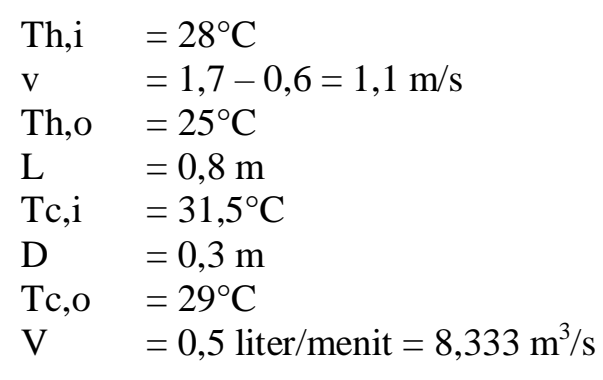

dengan:

Th,i = Temperatur udara masuk

Th,o = Temperatur udara dihasilkan

$\mathrm{Tc}, \mathrm{i}=$ Temperatu air masuk

$\mathrm{Tc}, \mathrm{O}=$ temperatur air keluar

$\mathrm{L} \quad=$ Panjang Prototipe Menara Pendingin

Mini

$\mathrm{D} \quad=$ Diameter Prototipe Menara Pendingin

Mini

$\mathrm{V} \quad$ = laju aliran volume air

$\mathrm{v} \quad=$ Kecepatan udara

\section{Perhitungan laju aliran massa udara (mh)}

$(\mathrm{mh})=\rho \cdot \mathrm{A} \cdot \mathrm{v}$

Penghitung temperatur rata-rata (Th)

$$
\begin{aligned}
\bar{T} h & =\frac{T h, i+T h, o}{2} \\
\bar{T} h & =\frac{28^{\circ} \mathrm{C}=25^{\circ} \mathrm{C}}{2} \\
\bar{T} h & =26,5^{\circ} \mathrm{C}
\end{aligned}
$$

Penghitung massa jenis udara

$\mathrm{T}(26,5)=\rho=1,178 \mathrm{~kg} / \mathrm{m}^{3}$

Dari tabel A-15 Properties of air 1 atm pressure

(Cengel, 2002)

\section{Perhitunagan laju aliran massa air (mc)}

$(\mathrm{mc})=\rho . \mathrm{V}$
A. Penghitung temperatur rata-rata $(\mathrm{Tc})$

$$
\begin{aligned}
\bar{T} h & =\frac{T c, i+T c, o}{2} \\
\overline{T h} & =\frac{31,5^{\circ} \mathrm{C}+29^{\circ} \mathrm{C}}{2}
\end{aligned}
$$

$$
T h=30,25^{\circ} \mathrm{C}
$$

B. Penghitung massa jenis air $(\rho)$

$\mathrm{Tc}=30,25$ maka $\rho=995,9 \mathrm{~kg} / \mathrm{m}^{3}$

Dari tabel A-9 Propertiesof saturated water (Cengel, 2002)

Jadi laju aliran massa air dapat (untuk $\mathrm{V}=0,5$ liter $/$ menit $=8,333 \mathrm{~m}^{3} / \mathrm{s}$ ) sebagai berikut :

$\mathrm{mc}=\rho . \mathrm{V}$

$\mathrm{mc}=995,9 \mathrm{~kg} / \mathrm{m}^{3} .8,333 \mathrm{~m} / \mathrm{s}$

$\mathrm{mc}=8298,83 \mathrm{~kg} / \mathrm{s}$

\section{Perhitungan Hasil Pengukuran Perpindahan Panas Plat Datar}

\section{Bilangan reynold}

Diketahui :

$$
\begin{array}{ll}
\mathrm{v} & =1,7-0,6=1,1 \mathrm{~m} / \mathrm{s} \\
\mathrm{D} & =0,3 \mathrm{~m} \\
\rho & =1,178 \mathrm{~kg} / \mathrm{m}^{3} \\
\mu & =0,000018
\end{array}
$$

$$
\begin{aligned}
\operatorname{Re} & =\frac{\rho \cdot v \cdot . D}{v} \\
\operatorname{Re} & =\frac{1,178 x 1,1 x 0,3}{0,000018}
\end{aligned}
$$

$\operatorname{Re}=21.596$

$\operatorname{Re}<$ dari 3600 maka bilangan laminar

\section{Bilangan Nusselt}

$\mathrm{Re}=21.596$

$\mathrm{D}=0,3 \mathrm{~m}$

$\rho$ udara $=1,174 \mathrm{~kg} / \mathrm{m}^{3}$

$\mathrm{k}$ udara $=0,000018 \mathrm{~kg} / \mathrm{m} . \mathrm{s}$

$$
\begin{aligned}
& N u=3,66+\frac{0,0668(D / L) \cdot \operatorname{Re} \cdot \operatorname{Pr}}{1+0,04[(D / L) \cdot \operatorname{Re} \cdot \operatorname{Pr})]^{2 / 3}} \\
& N u=3,66+\frac{0,0668(0,75) x(21 \cdot 596) x(0,72918)}{1+0,04[(0,75) x(21.596) x(0,72918))]^{2 / 3}}
\end{aligned}
$$

$N u=103,86$

Ditanyakan: 


$$
\begin{aligned}
& N u=\frac{h \cdot D}{k_{\text {udara }}} \\
& h=\frac{N u \cdot k_{\text {udara }}}{D} \\
& h=\frac{(103.86) x(0,02559)}{0,3}
\end{aligned}
$$

$h=8,859 \mathrm{~W} / \mathrm{m}^{2 \circ} \mathrm{C}$

Jadi koefisien perpindahan panasnya sebesar:

$$
h=8,859 \mathrm{~W} / \mathrm{m}^{2 \circ} \mathrm{C}
$$

\section{Laju Perpindahan Panas Pada Plat Datar}

$h=8,859 \mathrm{~W} / \mathrm{m}^{2 \circ} \mathrm{C}$

$A=0,25 \mathrm{~m}^{2}$

$\Delta T=31,5^{\circ} \mathrm{C}-29^{\circ} \mathrm{C}=2.5^{\circ} \mathrm{C}$

Maka:

$q=h . A \cdot \Delta T$

$q=8,859 \mathrm{~W} / \mathrm{m}^{2 \circ} \mathrm{C} \times 0,25 \mathrm{~m}^{2} \times 2.5^{\circ} \mathrm{C}$

$q=5,537 \mathrm{~W} / \mathrm{m}^{2 \circ} \mathrm{C}$

Jadi laju perpindahan panasnya sebesar $q=5,537 \mathrm{~W} / \mathrm{m}^{2 \circ} \mathrm{C}$

\section{Kesimpulan}

Dari hasil analisa dan perhitungan terhadap perencanaan Prototipe Menara Pendingin Mini (cooling tower) tipe plat datar, maka dapat disimpulkan bahwa:

1. Laju aliran perpindahan panas pada perencanaan Prototipe Menara Pendingin Mini (Prototype Mini cooling tower) tipe plat datar adalah $q$ sebesar $5,537 \mathrm{~W} / \mathrm{m}^{2 \circ} \mathrm{C}$

2. Koefisien laju aliran perpindahan panas pada perencanaan Prototipe Menara Pendingin Mini (Prototype Mini cooling tower) tipe plat datar adalah $h$ sebesar 8,859 $\mathrm{W} / \mathrm{m}^{2 \circ} \mathrm{C}$

\section{Daftar Pustaka}

Cengel, Yunus. A (2002). Heat Transfer A Practical Approach. New York: Mc.GrawHill Companies Inc

Frank Kreith, Arko Prtijono M.Sc. (1997). Prinsip-Prinsip Perpindahan Panas. Jakarta:Erlangga.

Frank M. White.(1996). Mekanika Fluida Edisi Kedua Jilid 1. Jakarta:Erlangga
Frank P. Incopera. (2007). Foundamentals of Heat and Mass Transfer. United Stated of Amerika

J.P. Holman, Ir. Jasifi. (1997). Perpindahan Kalor. Jakarta : Erlangga

Mark W. Zemansky, Ph.D, Richard H. Dittman, Ph.D. (1997). Heat and Thermodynamics. Ney York: Mc. Graw-Hill Companies Inc

M.M. El-Wakil. (1984). Powerplant Technology Seonadi ${ }^{1, a}$, A.C Arya ${ }^{2, b}$, Zainulsjah ${ }^{3, c}$, Erens ${ }^{4 d}$. (2015). Pengaruh Debit Aliran Air Terhadap Proses Pendinginan Pada Mini Chiller. Banjarmasin : Proceeding Seminar Nasional Tahunan Teknik Mesin XIV (SNTTM XIV) 